\title{
Implementation of Robots in Spot Welding Process
}

\author{
Mrs Magar J.E ${ }^{1}$, Prof.Shelkikar R.P \\ ${ }^{1} E \& T C$, college of engg, Osmanabad/Dr.Bamu,India, \\ ${ }^{2}$ Associate Professor, college of enggOsmanabad/Dr.Bamu,India.
}

\begin{abstract}
Within industry many repetitive operations, such as pick and place, spot welding, and spraypainting, have been successfully automated. While the operations themselves are diverse, a common thread within nearly all of them is that the robot performing the task. From a control perspective, this means that the robot need only be controlled to follow a desired task.Robots are well-established in the material processing industry. They are used for cutting, welding and marking of work pieces made from diverse materials. In these applications it is important to move the focal spot of the welding exactly along the desired machining contour on the work piece. Due to their mechanical inertia, robot arms can not perform abrupt changes of velocity (direction and magnitude) even though this is frequently required in machining operations. In this paper a automation technique is proposed, which is intended to partly overcome the limitations of doing the same work by using manpower. The paper describes control strategy, which is based on plc automation and a real time interface to a standard robot controller. Simulation-based and experimental results are presented and the performance of the control strategy in various test scenarios is described
\end{abstract}

Key Words: Automation Control, , Programmable logic control Robotics and Automation, Robotic assembly.

\section{Introduction}

Nowadays there is tremendous change in technology used in any manufacturing company. Especially in automobile industries the competition is increased very much. Car manufacturers are producing large variety of products. And if they want to survive in this competition they have to be updated. This can be done only after giving quality products within the time. To fulfill these requirements companies are manufacturing different models by using same platform. This can be done by reducing time required for production. There must be flexibility of using same equipments for different models. So there is requirement of automation. The equipments used in automation are effective to produce at faster rates and with better quality. Automation is made by using different machines like CNC, putting conveyors for transfer systems. All these systems require PLC. Also most of the automobile industries use robots. Robots are used for making spot welding, painting, assembly, waterjet cutting, dispensing, handling parts. By using robots work is completed faster. Accuracy of work increases because robot works as per the program stored in it. There is no deviation in the position from programmed points. As software used in the robot is advanced the diagnosis is also very easy and faster.

\section{Introduction of PLC -}

More recently electricity has been used for control and early electrical control was based on relays. These relays allow power to be switched on and off without a mechanical switch. It I common to user relays to make simple logical control decisions. The development of low cost computer has brought the most recent revolution, The programmable logic controller. The PLC has become the most common choice for manufacturing controls. Some of the advantages of PLC are mentioned below.

1.Cost effective for controlling systems.

2.Flexible and can be reapplied to control other systems quickly and easily.

3.Computational abilities allow more sophisticated control.

4.Trouble shooting aids make programming easier and reduce downtime. 


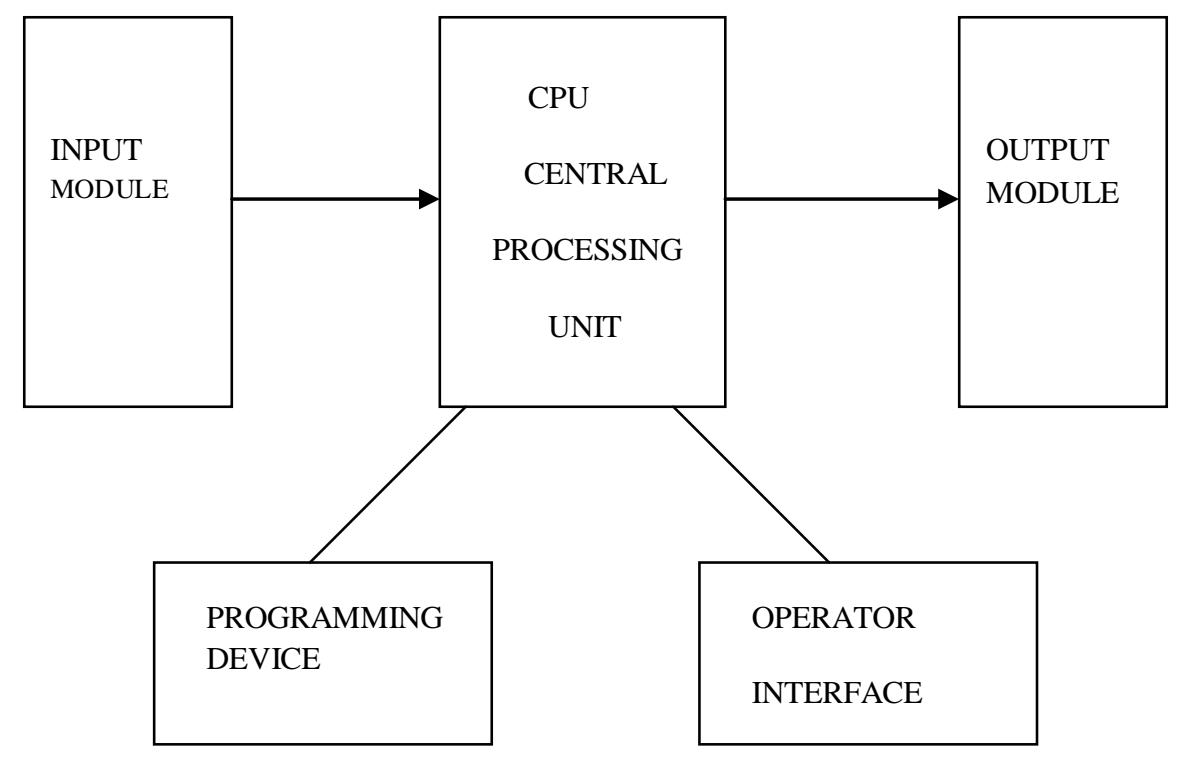

Fig1-block diagram of plc

\subsection{Hardware -}

The most essential components of PLC are

1) Power supply - This can be built into the PLC or be an external unit.Common voltage levels required by PLC are $24 \mathrm{vdc}, 120 \mathrm{vac}, 220 \mathrm{vac}$.

2) CPU - This is a computer where ladder logic is stored and processed.

3) Input / Output cards - A number of input and output terminals must be provided so that the PLC can monitor the process and initiate actions.

4) Indicator lights - These indicate the status of the PLC including power on, program running and fault. These are essential when diagnosing problem.

5) Rack - A rack is often large and can hold multiple cards. When necessary, multiple racks can be connected together. The input, output, power supply, CPU cards are located in the rack.

Programming device is used to make or change the program in PLC. It is not the part of PLC but is required to enable PLC. Operator interface is required to monitor or control the process. This is helpful to diagnose the problems.

\subsection{Software -}

A software based PLC requires a computer with an interface card which allows PLC to be connected with computer. A PLC program written in CPU can be read using software only. To find the problem in PLC program, to make changes in the program a software is must. Inputs to, and outputs from, a PLC are necessary to monitor and control a process.

\section{Robot programming -}

The robot programming is a part of experience. There are main four types of co-ordinate systems used for robot programming. The brief description of each system is given below.

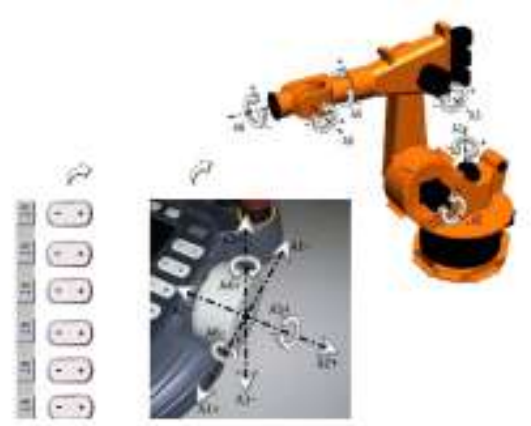

Fig2-co-ordinate System

There are main four types of co-ordinate systems used for robot programming. 
1.Joint co-ordinate system

2.World co-ordinate system

3. Base co-ordinate system

4.Tool co-ordinate system

IV. Application of process -

A welding gun is attached at end effector of robot and programmed to perform sequence of welds on car as it arrives on workstation. The welding gun consists of the pair of electrode and a frame to open and close electrodes. In addition large electric cables are used to deliver the current to the electrodes from welding controller. The welding with cables attached is quite heavy and can easily exceed 50-60 kg. To assist the operator in manipulating gun, the apparatus is suspended from an overload hoist system. Even with the assistance the spot welding gun represents the heavy mass and is difficult to manipulate by human worker at the high rates of production. There are often problems with the consistency of welded products made on such ive

As a result robots are introduced with great success on this type of production line to perform spot welding operations. Today the automobile manufacturers make extensive use of robots for spot welding.

V. Result-

Relative motion of robot along $\mathrm{x}, \mathrm{y}, \mathrm{z}$ asxis.Relative conditions of motors, \& sensors.

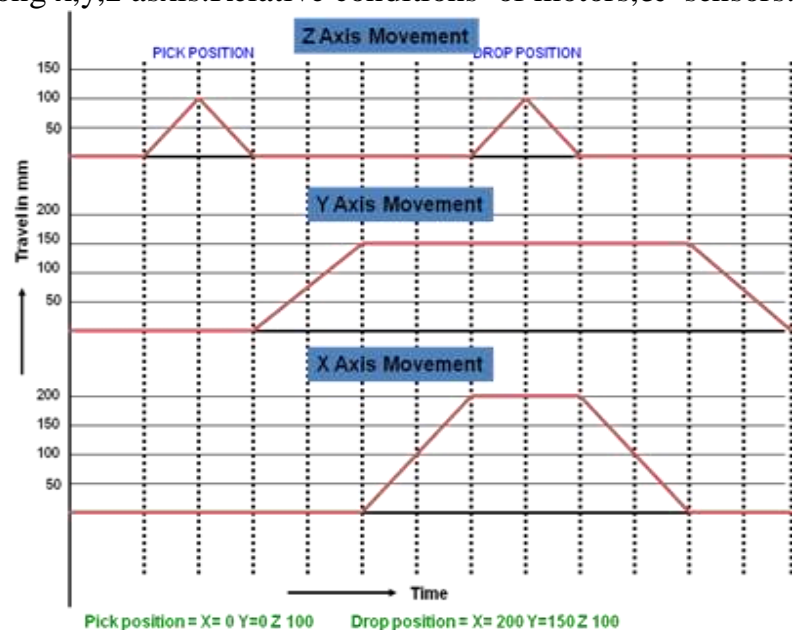

Fig3-Relative motions of robot along $\mathbf{x}, \mathbf{y}, \mathbf{z}$ axis

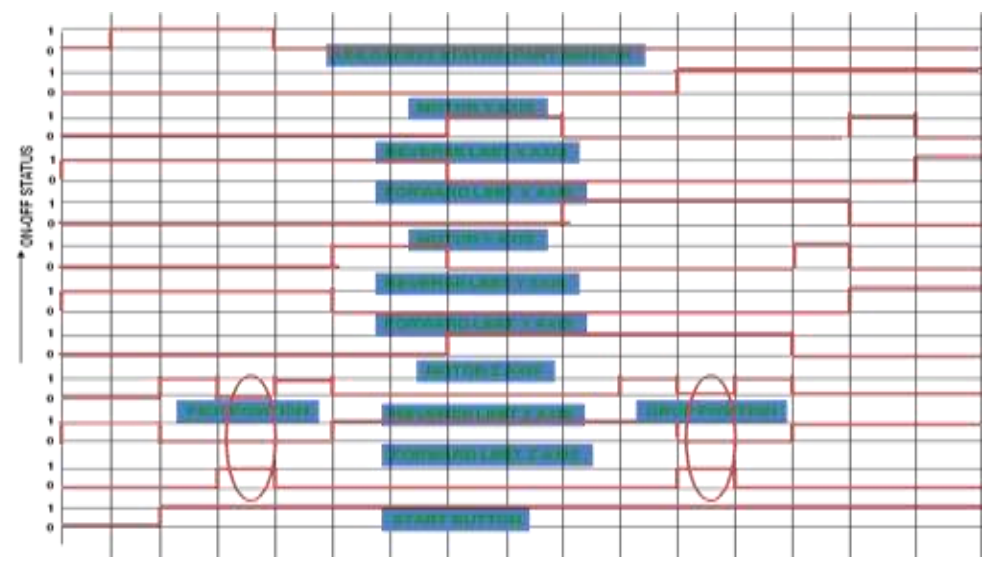

Fig.4-relative actions of motors $\&$ sensors

\section{Conclusion-}

The benefits that result from automation of the spot welding process by means of robots are improved product quality, operator safety and better control over production operation. Improved quality is in the form of more consistent welds, improved safety results because the human is removed, from a work environment where there are hazards from electrical shocks and burns. The 
use of robots in automatic lines using PLC controls are used for making spot welding for different models on same line.

\section{Scope for future study-}

The robot programming or study is not simple. Some fundamentals changes as application changes. Study of robot architecture is vary vast. All details can not be studied by doing just one project. Also the part of PLC programming is also depend upon experience.

\section{Referances-}

[1]. Hajduk M., Baláz $\square$ V.: Measurement deviation movement of robot Kuka from define trajectory with laser senzor ., IV medizná rodná konferencia , Mechanika z .67, Modulowe technologie i konstrukcje w budowie maszyn , Rzeszóv 2006, Polsko, str. 261264(3).

[2] Biagiotti, L., Zanasi, R., "Online trajectory planner with constraints on velocity, acceleration and torque", Industrial Electronics (ISIE), 2010 IEEE International Symposium on, On page(s): 274 - 279

[3] C. Blume and W. Jakob Programming Languages for Industrial Robots, 1986 :Springer-Verlag (3)

[4] I.Cox and N.Gehani "Exception handling in robotics", IEEE Computer, 1989

[5] J. J. Craig Introduction to robotics: mechanics and control, 1989 :Addison-Wesley

[6] J. Hallam "Autonomous robots: from dream to reality", Proceedings from $\backslash$ Robotikdagar, 1991

[7] J. L. Nevins Adaptive control, learning and cost effective sensor systems for robotics or advanced automation systems, 1984 